\title{
Effects of the Rotating Arc Technique on the GMA Welding Process
}

Régis Henrique Gonçalves e Silva ${ }^{1}$ (D), Mateus Barancelli Schwedersky ${ }^{1}$, Arthur Gustavo Moreira Santos ${ }^{1}$, Marcelo Pompermaier Okuyama ${ }^{1}$

${ }^{1}$ Universidade Federal de Santa Catarina - UFSC, Departamento de Engenharia Mecânica, Florianópolis, SC, Brasil.

How to cite: Silva RHG, Schwedersky MB, Santos AGM, Okuyama MP. Effects of the rotating arc technique on the GMA welding process. Soldagem \& Inspeção. 2020;25:e2519. https://doi.org/10.1590/0104-9224/SI25.19

\begin{abstract}
Recent profusion of advanced GMAW process variants impairs understanding of the nature of each one, with the arc rotation technique among them. This paper's objective is investigating influences of wire-electrode rotation over metal transfer mode and melting rate. A bead on plate experimental matrix was performed and electrical signals acquired in synchronicity with high speed videography. Impacts of electrode rotation were observed on welding voltage and current, whereby rotation speed exerts marked influence. Droplet short-circuiting frequency was affected, culminating in free-flight transfer mode for higher rotation speeds. Increase of melting rate was observed for lower electrical power, indicating efficiency enhancement of the process. Moreover, arc rotation proved to expand controllability of the thermal development of the workpiece. Results are supported by videothermography.
\end{abstract}

Key-words: Rotation speed; Metal transfer modes; SpinArc; MIG/MAG; Automated welding torch; Temperature profile.

\section{Introduction}

The evolution of the GMAW process started because of the evolution of power sources with innovative electronic resources. Firstly, power sources were developed to allow manipulation of the current, in terms of polarity and intensity (application of diodes and switching thyristors), until its complete modulation, resulting on the technique of metal transfer control by means of pulsed current. In sequence, power sources allowed for the control of the welding current during short-circuiting metal transfer. Recently, technologies were developed for the control of the short-circuiting metal transfer, whereby the wire-electrode alternates in direction and changes in speed of feeding [1-3], an evolution in the domain of mechatronics. Within the development line of the GMAW process and the consequent launch of technologies, a welding system called SpinArc emerged recently, characterized by the mechanized rotation of the contact tip and, consequently, of the wire-electrode in its energized segment (stick out), as shown in Figure 1.
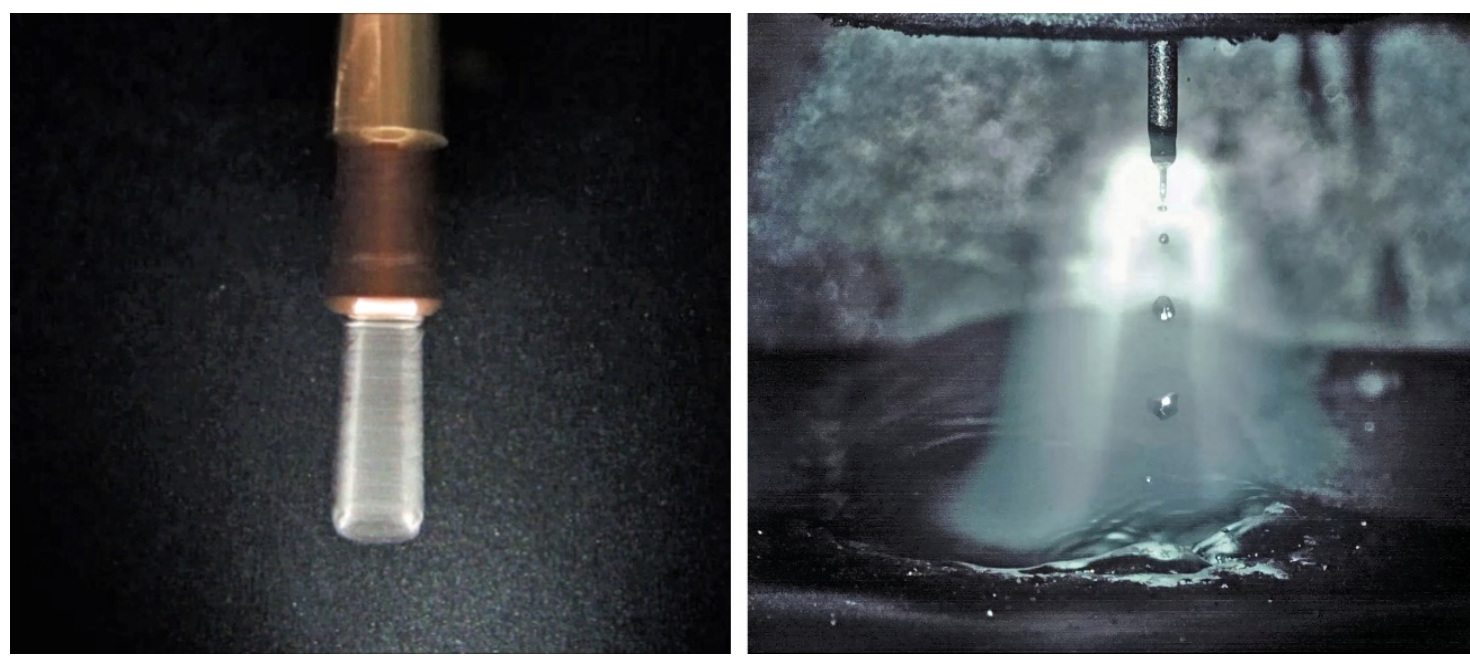

Figure 1. Rotating wire electrode technology; operation at $3000 \mathrm{rpm}$ (video attached) and rotating arc welding highspeed video frame (high speed videos available at LABSOLDA's website $[4,5]$ ). 
According to the manufacturer of the most widely known GMAW arc rotation system (Spinarc [1,2]), the technology finds distinctive applicability in welding operations using Narrow Gap techniques on heavy thickness plates. Advantages of this variant of the GMAW process that are claimed by its manufacturer span over productivity gains, such as the possibility of reduction of the bevel angle and also gains related to the mechanical/metallurgical properties, allied with lower susceptibility to defects such as lack of fusion $[3,6]$.

In general, a few studies have been found in reference to rotary electrode technology, however this studies do not bring much information about the physics of the process. Yang et al. [7] proposed in their research to evaluate the effects of the wire-electrode rotation speed with narrow gap techniques on the horizontal position. The researchers of this study were able to conclude that the welding process with rotation speeds $\mathrm{s}$ between 5 and $20 \mathrm{~Hz}$ result in a stable process, whereby no problems were observed regarding lack of fusion nor with the flow of the weld pool. When the rotation speed increased to values higher than $20 \mathrm{~Hz}$, the researchers observed the presence of lack of fusion on both sidewalls, along with a "side wall jump" of the electric arc. Zhang et al. [8] demonstrated effects of the rotation speed of the wire-electrode, regarding morphological aspects of the weld and process physics. These authors concluded that the rotation speed of the wire-electrode can change the weld penetration profile. For the non-rotation welding process, the wire-electrode stays stationary, and the penetration appear to be a finger shape. When the rotation speed increases, the penetration profile spreads itself onto the groove sidewalls. The researchers also reported enhancement of wire-electrode melting rate due to the increase in rotation speed, however they did not explain the effect responsible for this phenomenon. With the objective of producing a comparison between the conventional process and the rotational variant, Min et al. [9] performed welding tests on quenched and tempered low carbon alloy steels plates on the flat position using the Narrow Gap technique with a 60 groove angle. The authors concluded that the applied $60 \mathrm{~Hz}$ rotating electrode is an alternative for welding the mentioned materials, and mechanical tests also demonstrated a higher tensile strength and higher impact resistance for procedures performed with this technology. However, such studies do not provide information on the influence of the rotation speed of the wire-electrode on the metal transfer.

Regarding the modes of metal transfer of the GMAW process, it can be stated that short-circuiting is arguably the most used, being characterized by a low average welding current and a low average voltage, thus promoting low heat input when compared to other types of metal transfer (mainly spray). However, short-circuiting mode may be more prone to metal transfer instability and overall process irregularity. Large dimensions and asymmetry of droplets, as well as vibration of the melting pool, may lead to sporadic accidental/incipient short-circuits [10]. The break of the metal bridge occurs at high current peak values, which can lead to an abrupt metal transfer, generating micro explosions and spatter, and eventually, process instabilities and spatter contamination of the torch and peripherals.

An eventual progressive increase of the welding current leads to the so-called transition current (It), when an abrupt reduction of the droplet formation time takes place until its detachment, generating an increase in the transfer frequency and a reduction in the drop diameter, in a free-flight mode, called spray transfer [11], also known as spray. Some of the characteristics of this transfer mode are a full stability of the electric arc, absence of spatter, good wettability and it is also possible to operate with high welding speed and high melting rate. Despite its aforementioned advantages, the spray metal transfer mode incurs a large weld pool, with high fluidity, rendering it difficult to weld out of the flat position, and also leads to excessive melting in the case of thin sheets or root passes, due to the high value of transition currents. As an example, for a $1.2 \mathrm{~mm}$ diameter steel wire-electrode with a shielding gas composed of $98 \% \mathrm{Ar}+2 \% \mathrm{CO}_{2}$, the transition current exceeds 220 A [12].

In view of the aforementioned limitations of the GMAW process in the short-circuiting metal transfer mode (process instabilities and spatter emission in the arc extinguishing and arc restriking transients) and in the spray metal transfer mode (high transition currents, large weld pool, excess weld pool fluidity, overmelting/burnthrough of thinner plates or root passes), a question arises on the potential of the arc rotation technology to overcome them. Would it be possible to obtain a free flight metal transfer mode (without unstable short-circuiting transients) at lower currents (avoiding excess energy), as a result of the rotation of the wire-electrode? In face of this question and of the knowledge gap about the impact of the innovative wire-electrode rotation technique on the GMAW process, the aim of this work was set to study the influences of wire-electrode rotation on the electric arc behavior, by means of the oscillographic study of its parameters, on the thermal evolution of the workpiece and on the metal transfer pattern, by means of high speed videography and videothermography.

\section{Materials and Methodology}

The tests performed on the present work consisted on bead on plate welds in the flat position, whereby the rotation speed of the wire-electrode was changed and the other parameters remained constant. Acquisition of current and voltage signals was performed, as well as high-speed technical filming.

The GMAW system called SpinArc model MA - 400 developed by WeldRevolution was used, which has a maximum operating capacity of $300 \mathrm{~A}$ in a $100 \%$ duty cycle (air-cooled). The equipment allows to change the rotation speed of the wire-electrode, varying between 500 and $5500 \mathrm{rpm}$. The welding torch has a mechanical device that enables adjustment of the base diameter of rotation of the wire-electrode (the notation "base diameter" stems from the fact that the actual diameter of rotation differs from that regulated for different parameters of rotation. 
As the torch permits several sets of parameters with regard to the rotation speed and base diameter of rotation, the manufacturer presents guidelines for different applications. In order to perform overlay procedures, the base diameter of rotation should be adjusted in 7-8 mm operating with a lower rotation speed 500-1200 rpm. For operations with Narrow Gap techniques the manufacturer advises to use smaller base diameters of rotation, 1-4 mm, with the possibility to use higher rotation speeds.

The speed rotation of the wire-electrode is set by the potentiometer knob on the control panel of the system, where it is also possible to change the direction of the electrode's rotation. Another function available on the panel is the delay, allowing to start the wire-electrode to be rotated after a predetermined time.

As for the welding power source, an open architecture transistorized multiprocess electronic equipment IMC Digiplus A7, with a maximum operating capacity of up to $450 \mathrm{~A}$, was applied. The power source was operating in the constant voltage (CV) mode. For the execution of the welding trajectory, a Tartilope V2 bug-over-track robotic manipulator with two degrees of freedom ( $x$ and $y$ ), manufactured by the company SPS, was used. This manipulator maintains the welding speed and contact tip to workpiece distance (CTWD) constant.

For data acquisition, the Portable Acquisition System - SAP of the manufacturer IMC was used. The system performs the acquisition of welding current, voltage and wire feed speed at a frequency of $5 \mathrm{kHz}$. The acquired data are treated and arranged in graphs and histograms, allowing detailed analysis of the welding procedure performed. In addition, specific sections can be analyzed independently of the other stretches acquired, which allows a detailed verification of some event occurred. For high-speed videography, an IDT model camera, Y4S2, was used with a maximum resolution at 4500 frames per second of $1016 \times 1016$.

The test specimen used was AISI 1020 steel, and measured $200 \times 50 \mathrm{~mm} \times 9,525 \mathrm{~mm}$. The wire-electrode used was the AWS ER70S-6,1.2 mm diameter. Gas shielding was performed with the mixture $92 \% \mathrm{Ar}, 8 \% \mathrm{CO}_{2}$ and flow rate of $25 \mathrm{~L} / \mathrm{min}$ measured at the tip of the torch with a flowmeter. The CTWD and the torch angle were respectively $15 \mathrm{~mm}$ and $90^{\circ}$ relative to the workpiece.

Aiming to investigate possible changes on the welding process resulting from the change of the rotation speed of the wire-electrode, tests with 5 different electrode rotation frequencies were carried out (0; 1000; 2000; 3000; 4000 RPM). A base diameter of rotation of $3.0 \mathrm{~mm}$ was adjusted, according to preliminary tests previously performed on Narrow Gap welding techniques, so that the electrode did not touch on the sidewalls.

Table 1 shows the electrical parameters selected on the power source. The parameters Ks and Kd are variables that allow for the adjustment of the welding current upslope and downslope speeds during short-circuit metal transfer (inductance).

Table 1. Electrical parameters selected on the power source for the short-circuit metal transfer.

\begin{tabular}{cccccc}
\hline Metal transfer & Ua $(\mathbf{v})$ & Wfr $(\mathrm{m} / \mathrm{min})$ & Ws $(\mathbf{c m} / \mathbf{m i n})$ & Ks & Kd \\
Short arc & 21.5 & 4.5 & 28 & 70 & 90 \\
\hline
\end{tabular}

\section{Results and Discussion}

Figure 2 shows the signals acquired on the experiments, where it can be observed that the increase of the rotation speed on the wire-electrode causes changes in both the oscillographic stability of the process and notably in the metal transfer mode. The oscillograms show that as the rotation speed of the wire-electrode increases, from $3000 \mathrm{rpm}$ to $4000 \mathrm{rpm}$, a reduction in the short-circuit frequency happens indicating that the metal transfer mode is changing from short-circuit to spray, without changing any parameters on the power source (under welding currents below the transient current, which will be discussed below). 


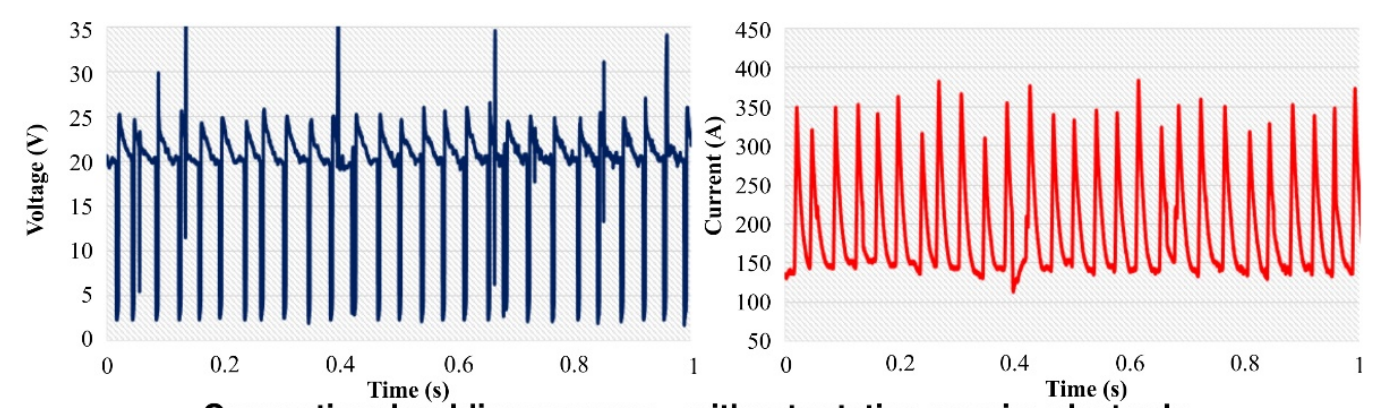

Conventional welding process - without rotation on wire-electrode
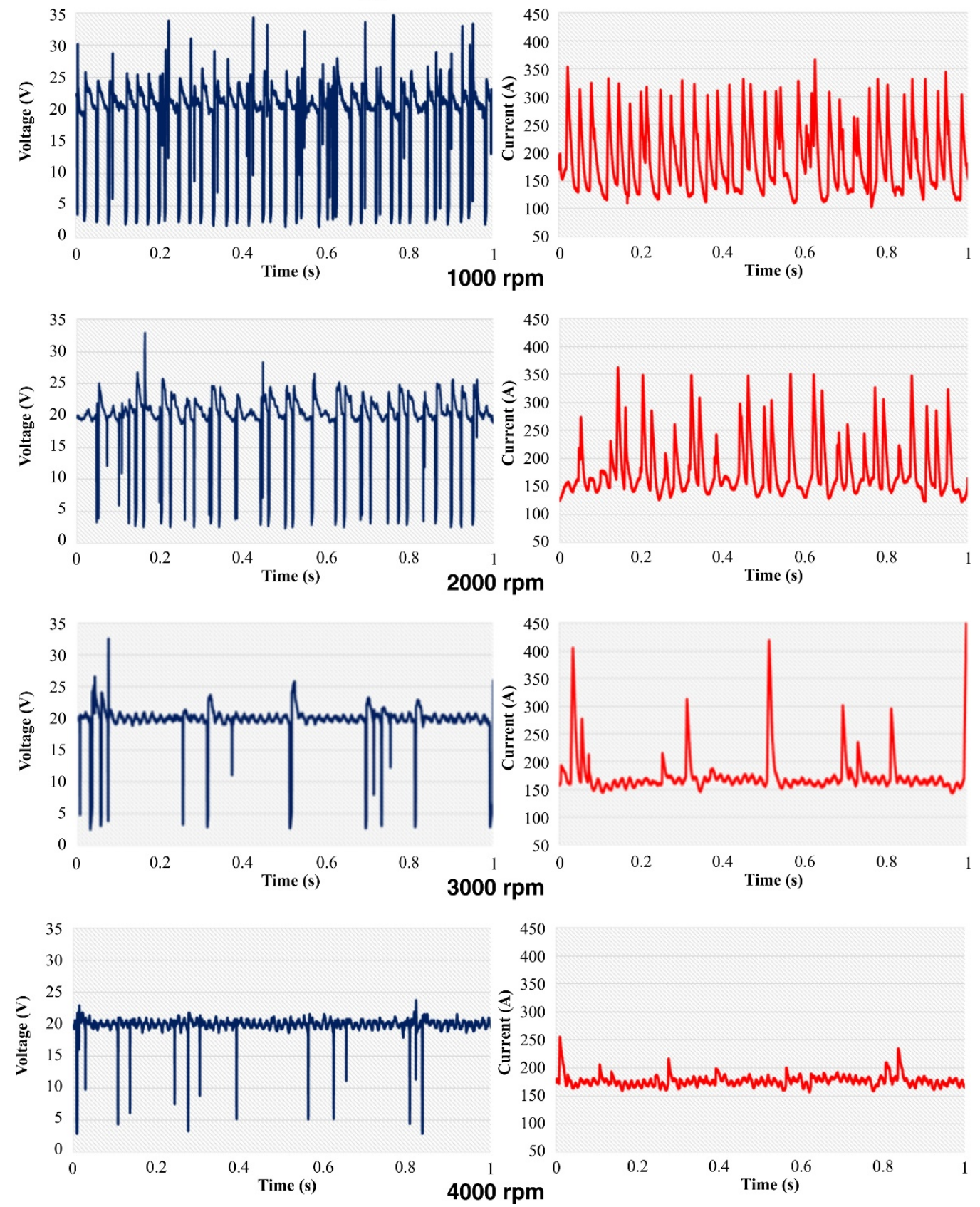

Figure 2. Oscillograms showing the behavior of the electrical signals as a function on speed rotation of the wire-electrode without any changes on the parameters on the power source. $\mathrm{Ua}=21.5 ; \mathrm{Wfs}=4.5 ; \varnothing=3$.

In relation to the average values acquired, the observation made is that the increase in the rotation speed results in a slight voltage variation and arc length increase, despite the fact that the set voltage (Ua) was the same for all tests (as was the wire feed speed, $\mathrm{Wfs}$ ). In relation to the welding current, a $15 \%$ decrease $(20 \mathrm{~A})$ between the extremes of the adjusted rotation speed ( 0 and $4000 \mathrm{rpm}$ ) was observed. These behavior of the electric variables were somewhat unexpected and can be explained by 
the following standpoint. In the constant voltage process (CV), the actual measured average voltage is not identical to the adjusted voltage in the welding power source, because the actual measured average voltage will indeed depend on several factors, as arc length, frequency and duration of short-circuits and cables length, for instance... For the studied case, rotation resulted in increase of arc length and a reduction of the short-circuits frequency.

With regard to the reduction of the average value of welding current, it is possible to state the following analysis: one of the factors that impact the average current is the high current values at the end of the current rise during the short-circuit, so called peaks. When there is a decrease of short-circuits frequency, there is a smaller number of moments in which the current remains at high values (less current peaks), thus resulting in a lower average value.

Two are the feasible options to restore the arc length, one simply by decreasing the voltage adjusted value on the power source, another by increasing the wire feed speed. That is, it was observed that the increase on rotation speed of the wire-electrode permits melting the same amount of wire with less electrical power than the resultant for lower frequencies or absence of rotation (Figure 3).

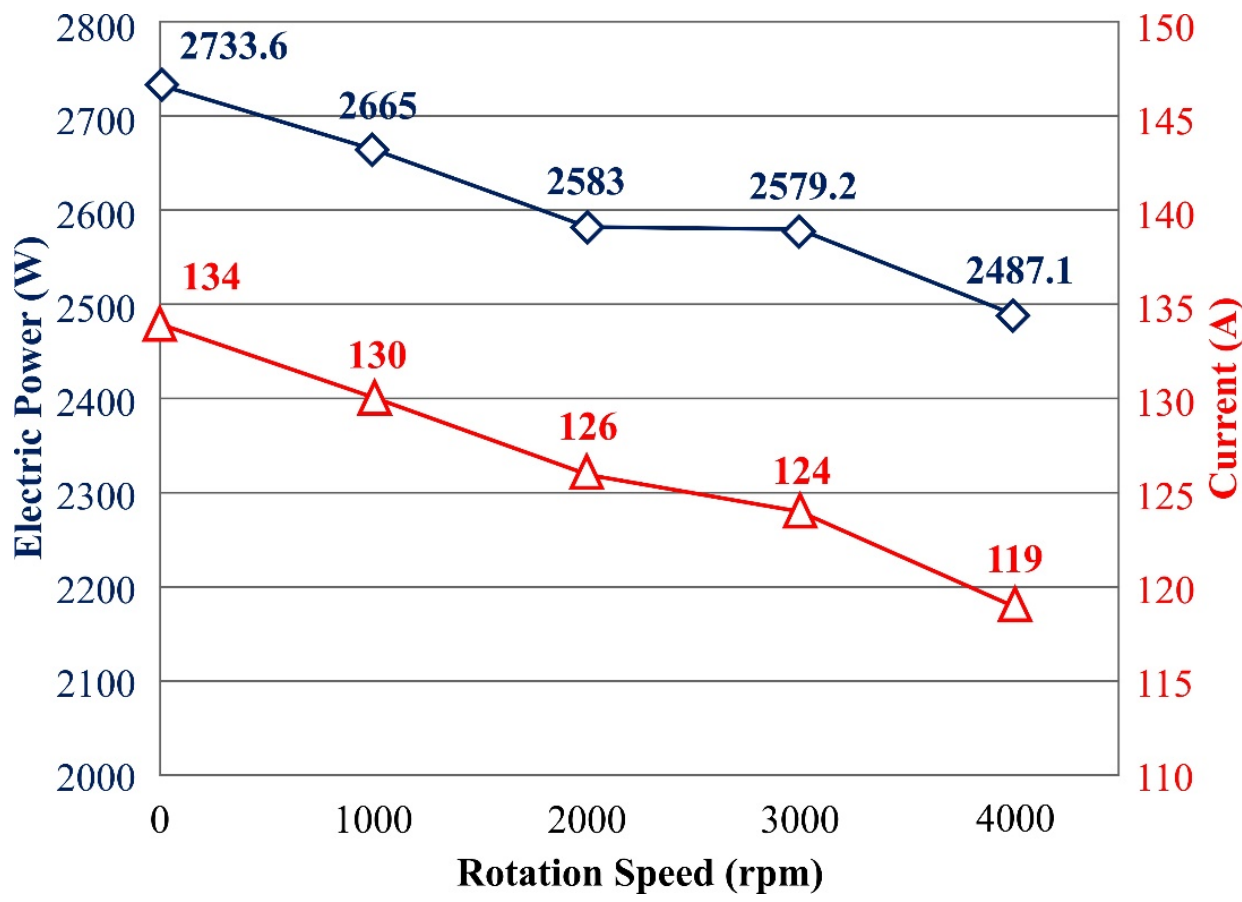

Figure 3. Electrical parameters (acquired from SAP) tests with short-circuit metal transfer.

High-speed videographic analysis allows to hypothesize on the effect of increase in the melting rate. It is known that the effective contribution of the anodic heating to the melting of the wire-electrode (which is the predominant heat source for wire melting, for most of process application conditions) acts indirectly between arc and solid wire. The anode heating is produced at the arc-anode coupling on the lower surface of the droplet and conveyed via convection through the molten droplet to the liquid-solid interface to the solid end of the wire, where it, added to the Joule heating of the wire-electrode stick-out, causes its melting $[13,14]$.

The droplets, in turn, are overheated by effects of electronic condensation and heat transfer from the arc [13,14], generating temperature and surface tension gradients, giving rise to the movement of the fluid that forms the drop. When rotation of the wire-electrode is applied at high speed, a velocity component tangential to the rotation is imposed on the plane of rotation. Due to the constant growth of the droplet, a droplet oscillation component tangential to the rotation occurs in the plane of rotation. This effect forces a displacement of part of the liquid-solid interface to the side surface of the wire-electrode, increasing heat transfer from the overheated droplet to the solid material, increasing its melting rate. The effect can be observed on the sequence of frames shows in Figure 4. Arc-anode coupling geometry plays significant role in the efficiency of the heat transfer from the anode region to the solid end of the wire (liquid-solid interface) and in its melting efficiency, as the formation of the "mesospray" condition described in the work of Kiyohara et al. [15]. Arc rotation may have a further influence in this effect too, changing the arc-anode coupling properties. However, investigations on this particular issue shall demand special and specific imaging technique (LASER illumination and high speed videography parameterization) for proper arc-anode coupling observation and shall be object of future papers. 

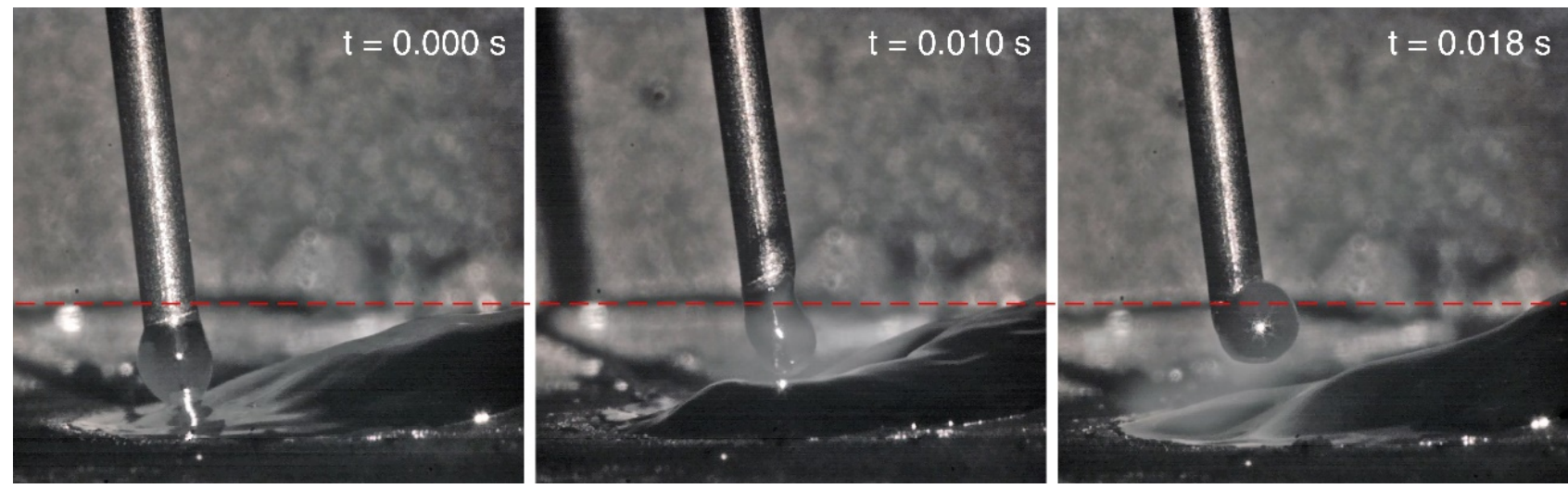

Figure 4. Sequence of high-speed frames, indicating displacement of part of the solid-liquid interface between droplet and electrode wire to the side of the solid material $-3000 \mathrm{rpm}$; base diameter of rotation $=3.0 \mathrm{~mm} ; \mathrm{Im}=124 \mathrm{~A} ; \mathrm{Ua}=20.5 \mathrm{~V} ; \mathrm{Wfs}=4.5 \mathrm{~m} / \mathrm{min}$.
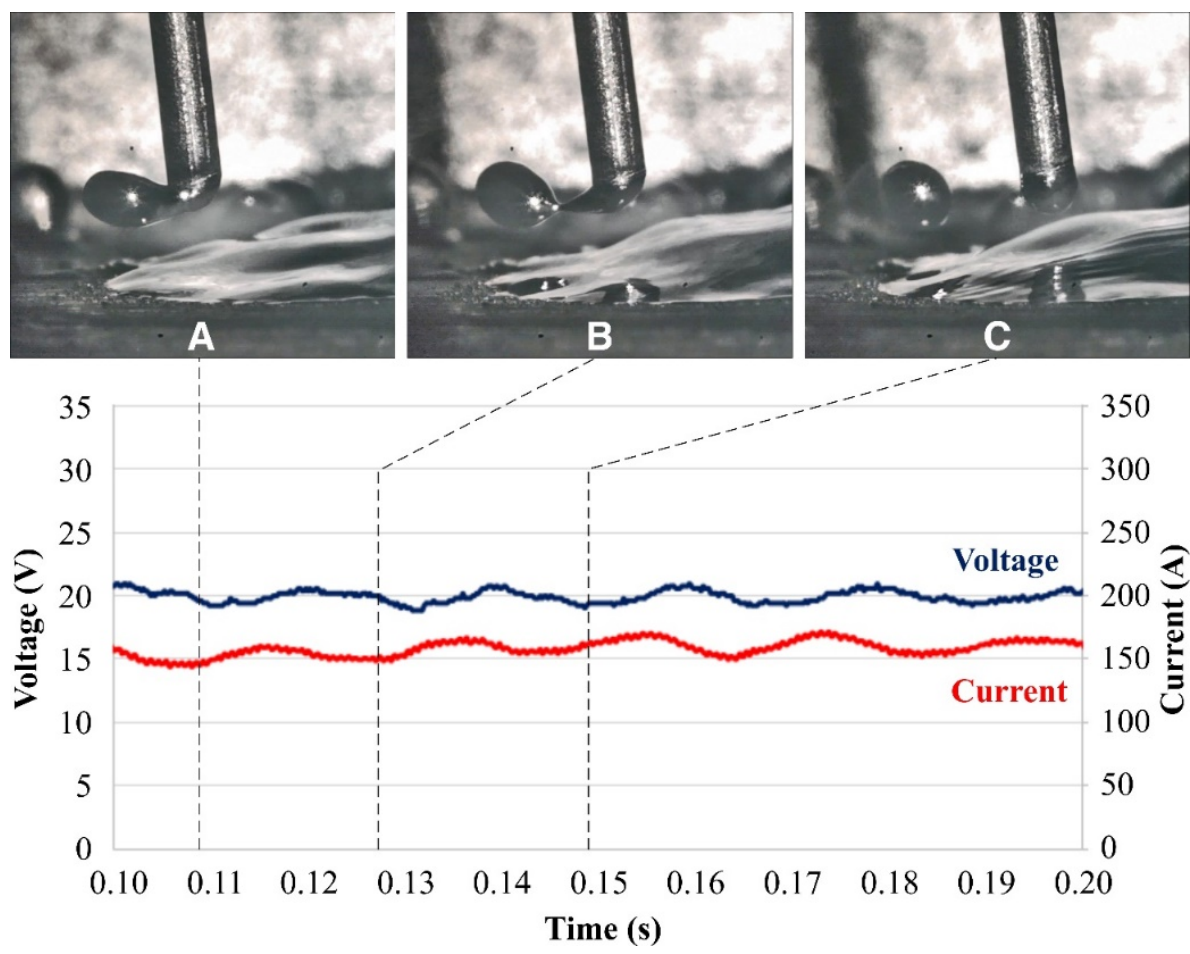

Figure 5. Frames of high-speed film showing the metal transfer with electrical signals. $\mathrm{W}=3000 \mathrm{rpm}$; base diameter of rotation $=3 \mathrm{~mm}$; $\mathrm{Im}=124 \mathrm{~A} ; \mathrm{Ua}=20.5 \mathrm{~V} ; \mathrm{Wfs}=4.5 \mathrm{~m} / \mathrm{min}$ (high speed videos available at LABSOLDA's website [16]).

It is noteworthy that the metal transfer transitions to the free flight mode for higher rotation speed of the wire-electrode, although the average welding current value is below the transition current for the specific combination wire (material and diameter) and gas. Hence, a marked influence of the rotation technique of the wire-electrode on the physical behavior of the process, especially in the melting and metal transfer phenomena, is stablished.

In view of the results obtained with the rotation speed of the wire-electrode at $3000 \mathrm{rpm}$, where the metal transfer seems to have ceased to contain short-circuits, high speed videography was performed with synchronized welding electrical data acquisition for a wider picture of the effect, and the results are exposed in Figure 5 (and corresponding video). The results corroborate the aforeproposed hypothesis for the effect of arc rotation on metal melting and transfer, amplifying the traditional knowledge regarding metal melting and transfer the GMA welding process [17-19]. Considering these perceptions, it can be understood that the action of the centrifugal force (pseudo-force arising from the rotation of the wire-electrode) tends to be another force acting on the metal transfer in order to assist the detachment of the drop, without the need for high currents to transfer a drop by free flight (without short-circuit).

Within the balance of forces theory, the main forces acting on the droplet in the GMA welding process are the forces of electromagnetic origin, usually favorable to the detachment, and the force due to surface tension, that tends to retain the drop at the tip of the wire-electrode, besides further influences of less impact (for the conditions of this work) of gravity, gas drag and expansion force from metal vaporization $[20,21]$. At present, however, in the case of a technology capable of providing 
continuous high speed rotation of the wire-electrode, it is understood that there is a change in the state of forces acting on the metallic droplet. Rotation of the wire-electrode imposes a tangential velocity to the droplet (about $1.25 \mathrm{~m} / \mathrm{s}$, at $4000 \mathrm{rpm}$ and base diameter of rotation position of $3 \mathrm{~mm}$ ), of magnitude similar to its axial displacement velocity. The centripetal acceleration (and the centripetal force) remains active, through the force of surface tension retaining the droplet to the wire-electrode, until the droplet detaches, due to the forces favorable to detachment, to which now the inertia of the droplet is added with its tendency to follow a tangent to rotation trajectory. In this way, the centrifugal force (resulting pseudo-force) starts to act as another force that contributes to the detachment of the metallic droplet. Figure 6 shows schematically the major forces acting on droplet detachment by operating with rotary electrode technology. Together with the larger average arc diameter obtained by the rotation of the electrode, this factor contributes to a good fusion of the joint sidewalls, especially in cases of narrow joint configurations.

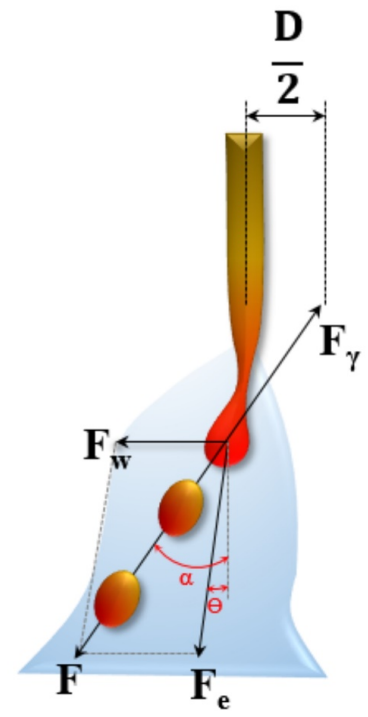

$\mathrm{F} \gamma=$ Resultant retaining force due to Surface Tension

$\mathrm{Fe}=$ Resultant detaching force from electromagnetic origin

$\mathrm{FW}_{\mathrm{W}}=$ Force componente from wire-electrode rotation

$\mathrm{F}=$ Resultant detachment force

Figure 6. Schematic representation of the action of the centrifugal pseudo-force, due to the rotation of the wire-electrode, acting on the detachment of the droplet (only the main acting forces are depicted; further forces of lower impact - for the conditions of this work- are omitted for the sake of illustration simplicity).

Additionally to the investigation on the effects of GMAW arc rotation on melting and transfer mode characteristics, study on the thermal influences over the weld pool are considered of high relevance, since they determine the resulting bead geometry and integrity. In this regard, qualitative passive videothermography was performed, showing that arc rotation leads to changes in temperature profile of the workpiece, indicating broader temperature profile and wider heat distribution (Figure 7). A deeper assessment of these matter shall be carried out in future work, considering hydrodynamic and heat transfer effects of arc rotation and derived transfer mode over weld pool temperature and convection, as well as over workpiece temperature.

The wider heat distribution seems to be beneficial for narrow groove applications, by rendering more robustness to the melting of the joint sides, preventing lack of fusion. Figure 8 (high speed video attached) depicts the arc inside a narrow groove joint and the weld result. 

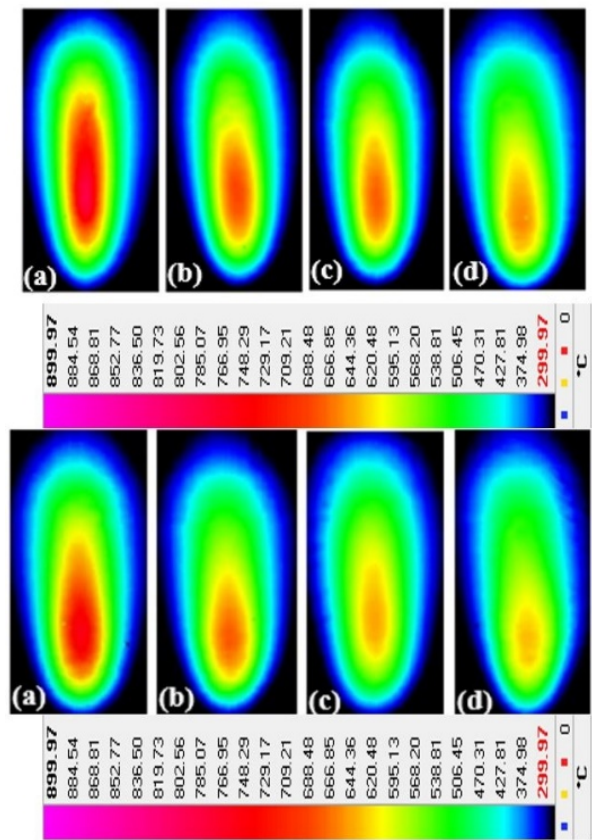

\section{@ 1000 RPM}

\section{a) Conventional - without rotation of wire}

b) base rotation diameter $=1.0 \mathrm{~mm}$

c) base rotation diameter $=2.0 \mathrm{~mm}$

d) base rotation diameter $=4.0 \mathrm{~mm}$

\section{base rotation diameter $=3.0 \mathrm{~mm}$}
a) 500 RPM
b) 1000 RPM
c) $1500 \mathrm{RPM}$
d) $2000 \mathrm{RPM}$

Figure 7. Qualitative passive thermograms, showing arc rotation thermal effects over the workpiece temperature profile.
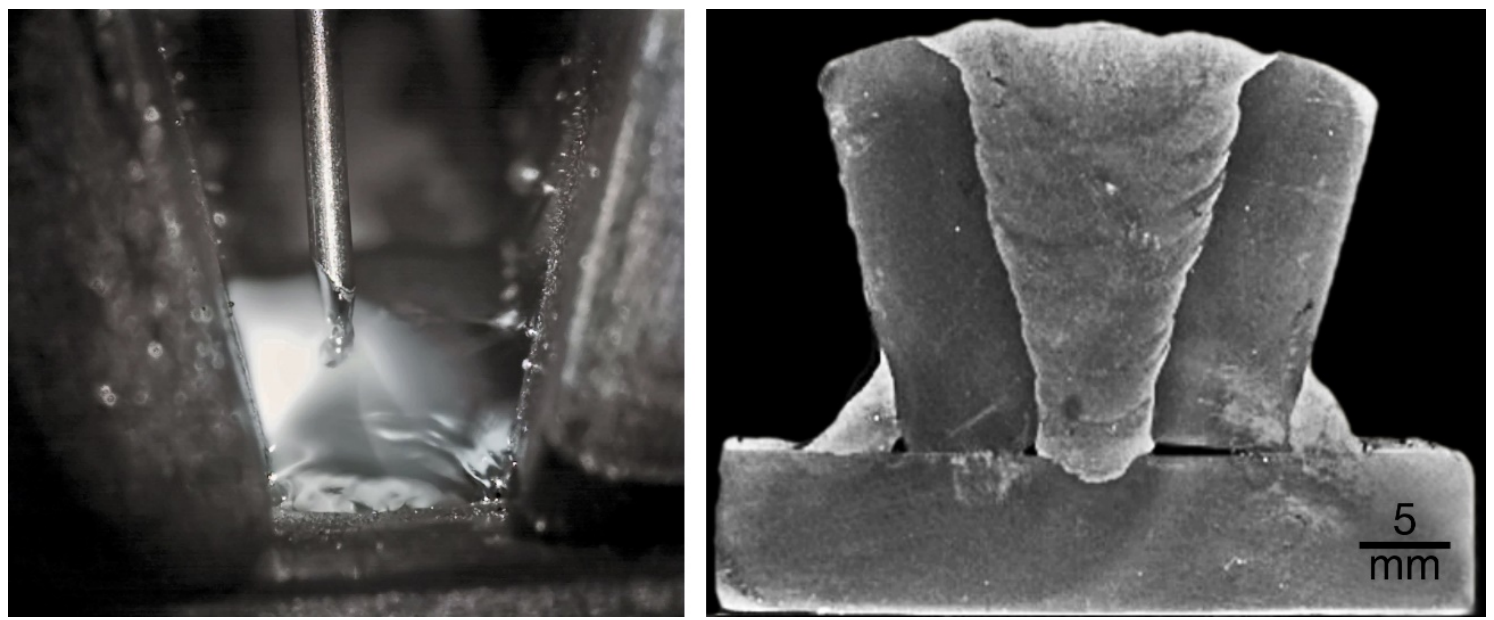

Figure 8. Highspeed videography frame (high speed videos available at LABSOLDA's website [22]) and weld cross section resultant from arc rotation

\section{Conclusions}

The present work assessed the influence of arc rotation and rotation speed of the wire-electrode on its melting rate and metal transfer on the GMAW process. Through the analysis of the experimental results, it was possible to conclude that:

- In terms of oscillographic behavior, the rotation of the wire-electrode changes the electrical signals of the welding process, yielding a reduced average welding current (due to the reduction of occurrences of current peaks) and an increased average voltage (due to the reduction of the voltage occurrence of voltage breakdowns and increase in arc length), as results of increase of rotation speed, both effects being due to the reduction of the occurrence of short-circuits.

- The arc rotation technique allows for a free flight metal transfer mode (without unstable short-circuiting transients) at lower welding currents than the original transition current (avoiding excess energy), up from 3000 rpm, under the conditions of these experiments. These are hence seen as benefits for orbital welding and for Narrow Gap/Narrow Groove configurations (possibility of welding out of the flat position with good stability, less proneness to root pass burnthrough, besides good fusion of both sidewalls and less proneness to lack of fusion, obtained by the greater diameter of action of the arc and lateral directioning of the detached droplets. Hereby, the observed wider heat distribution seems also to be beneficial).

- Arc rotation by means of wire-electrode rotation also interferes in the heating and melting efficiency of the wire, as this technique promotes an increase in the heat transfer through convection from the liquid droplet to the solid wire. Obtaining determined melting rates with lower currents and electric power than the conventional process indicates better performance of the rotational wire-electrode technology in terms of thermal efficiency and productivity. 


\section{Acknowledgements}

The authors thank the Welding and Mechatronics Institute (LABSOLDA) staff and IMC Soldagem for the technical support and the Brazilian R\&D sponsoring agencies PETROBRAS, FINEP, CNPq and CAPES.

\section{References}

[1] Kelley D. Operation manual: MA-400TM Air-Cooled SpinArc ${ }^{\circledR}$ Welding Torch. Frederick, MD: SpinArc; 2016.

[2] Funderburk S. SpinArc ${ }^{\mathrm{TM}}$ welding system explained. Welding Journal. 2015;(June):34-38.

[3] WeldRevolution. Experimental study of SpinArc ${ }^{\mathrm{TM}}$ technology. CWA Journal. 2018:12-17.

[4] Universidade Federal de Santa Catarina, Instituto de Soldagem e Mecatrônica - LABSOLDA. 2020 [access 22 may 2020]. Available from: https://labsolda.ufsc.br/perm/si-2020-0019/figure-1a-video.mp4

[5] Universidade Federal de Santa Catarina, Instituto de Soldagem e Mecatrônica - LABSOLDA. 2020 [access 22 may 2020]. Available from: https://labsolda.ufsc.br/perm/si-2020-0019/figure-1b-video.mp4

[6] Funderburk S. A new spin on welding. World Pipelines. 2015;3:1-4.

[7] Yang CL, Guo N, Lin SB, Fan CL, Zhang YQ. Application of rotating arc system to horizontal narrow gap welding. Science and Technology of Welding and Joining. 2009;14(2):172-177. http://dx.doi.org/10.1179/136217108X388651.

[8] Zhang H, Chang Q, Liu J, Lu H, Wu H, Feng J. A novel rotating wire GMAW process to change fusion zone shape and microstructure of mild steel. Materials Letters. 2014;123:101-103. http://dx.doi.org/10.1016/j.matlet.2014.03.018.

[9] Min D, Xin-hua T, Feng-gui L, Shun Y. Welding of quenched and tempered steels with high-spin arc narrow gap MAG system. International Journal of Advanced Manufacturing Technology. 2011;55(5-8):527-533. http://dx.doi.org/10.1007/s00170-010-3052-1.

[10] Zuruba I. Factors governing metal spatter during welding with short circuiting. Automatic Welding. 1974;(8):71.

[11] Lowke JJ. Physical basis for the transition from globular to spray modes in gas metal arc welding. Journal of Physics. D, Applied Physics. 2009;42(13):135204. http://dx.doi.org/10.1088/0022-3727/42/13/135204.

[12] Wainer E, Brandi SD, Mello FDH. Soldagem: processos e metalurgia. São Paulo: Edgard Blucher; 1992.

[13] Lesnewich A. Control of melting rate and metal transfer in gas-shielded metal-arc welding part I: control of electrode melting rate. Welding Research. 1958;(Suppl): 343-353.

[14] Waszink JH, Van den Heuvel GJPM. Heat generation and heat flow in the filler metal in GMA welding. Welding Journal. 1982;61(8):269280.

[15] Kiyohara M, Yamamoto H, Harada S. Melting characteristics of a wire electrode in the MIG-welding of aluminum. Arc Physics and Weld Pool Behaviour. 1979:165-175.

[16] Universidade Federal de Santa Catarina, Instituto de Soldagem e Mecatrônica - LABSOLDA. 2020 [access 22 may 2020]. Available from: https://labsolda.ufsc.br/perm/si-2020-0019/figure-5-video.mp4

[17] Liu S, Siewert TA. Metal transfer in gas metal arc welding: droplet rate. Welding Journal. 1989;68(2):51-58.

[18] Siewert TA. Process control of GMAW: sensing of metal transfer mode. Welding Journal. 1990;(April):1103-1108.

[19] Kim Y-S, Eagar TW. Analysis of metal transfer in gas metal arc welding. Welding Journal. 1993;72:269s-278s.

[20] Scotti A, Ponomarev V. Soldagem MIG/MAG: melhor entendimento, melhor desempenho. 2. ed. São Paulo: Artliber; 2008.

[21] Den Ouden G. Physical aspects of arc welding: proceedings of seminar in honour of J.F. Lancaster, 1 September 1993. Glasgow: National Library of the Netherlands; 1993.

[22] Universidade Federal de Santa Catarina, Instituto de Soldagem e Mecatrônica - LABSOLDA. 2020 [access 22 may 2020]. Available from: https://labsolda.ufsc.br/perm/si-2020-0019/figure-8a-video.mp4 